\title{
Las nonatas ordenanzas del Consejo de Indias de Carlos IV
}

\author{
Rafael García Pérez \\ Dpto. de Historia del Derecho. Facultad de Derecho \\ Universidad de Navarra
}

Con el fin de actualizar las ordenanzas del Consejo de Indias de 1636, durante el reinado de Carlos IV se constituyó una Junta integrada por consejeros de Indias. A lo largo de treinta y dos sesiones, esta Junta examinó cada una de las antiguas ordenanzas y propuso las modificaciones pertinentes. Gracias a un informe inédito de Manuel José de Ayala, localizado en el Archivo General de Indias, hemos podido conocer el contenido de cada una de estas sesiones. El estudio de estos trabajos proporciona abundantes luces para determinar el Derecho que efectivamente regía la vida de este importante Consejo en el siglo XVIII y conocer la organización y el funcionamiento de este Supremo Tribunal que aparece dotado de una gran vitalidad en esta época. Desgraciadamente, la Junta se extinguió en 1802, sin que se llegasen a promulgar las nuevas ordenanzas.

\section{Introducción}

Una de las más eficaces vías de aproximación al estudio de cualquier institución es el análisis de la normativa que regula su organización y funcionamiento interno. En estos casos, sin embargo, es conveniente constatar, con el estudio directo de las fuentes, la adecuación de la práctica real a las previsiones normativas, para formarse una idea de la institución que sea acorde con la realidad del momento.

En el presente trabajo pretendemos abordar el estudio del proceso de actualización de las ordenanzas del Consejo de Indias de 1636, que se intentó realizar a finales del siglo XVIII por explícito deseo de Carlos IV. Como el propio título de este artículo expresa, dicha renovación no se llevó a término y esas nuevas ordenanzas no llegaron a ver la luz. Con todo, consideramos que el análisis de los trabajos que la Junta de ministros del Consejo de Indias, encargada de llevar a cabo esta actualización, realizó es sumamente interesante para comprobar la vigencia efectiva, en las postrimerías del siglo XVIII, de las antiguas ordenanzas de 1636, y conocer de esta manera la normativa que realmente regía la vida del Consejo en dicha centuria. Además, estamos convencidos de que ésta puede ser una interesante vía de acceso al conocimiento del Supremo Tribunal de Indias en sus últimos años de esplendor. ${ }^{1}$

1 Hemos tenido conocimiento de los trabajos de la Junta encargada de actualizar las ordenanzas del Consejo de Indias, a partir de un compendio realizado por Manuel José de Ayala. Archivo General de Indias (AGI), Indiferente General, 886. Informe de M. J. de Ayala, 25 de marzo de 1802. 
En la realización de este trabajo nos han sido de una enorme utilidad los comentarios a la Recopilación de leyes de Indias de Manuel José de Ayala, ${ }^{2}$ como complemento ideal de los trabajos de la Junta encargada de la elaboración de las nuevas ordenanzas. En este sentido, dado que las ordenanzas del Consejo de Indias de 1636 fueron incorporadas a la Recopilación de 1680, los apuntes de Ayala a estos títulos esclarecen las decisiones adoptadas en cada momento por la Junta y aportan, en todo caso, elementos nuevos de juicio para la valoración del Derecho aplicable al Consejo en la segunda mitad del siglo XVIII.

Con carácter meramente introductorio, y para facilitar la aproximación al estudio del proceso actualizador de las ordenanzas, que se abordará posteriormente, vamos a referirnos brevemente en este apartado a la historia de dicha legislación, desde la fundación del Consejo en 1524.

Las primeras ordenanzas del Consejo de Indias fueron promulgadas en 1542 a raíz de una visita realizada a este tribunal. Estas ordenanzas, conocidas como Leyes Nuevas, en cuya formación no participó el Consejo, no sólo regulaban aspectos relativos a la organización y funcionamiento interno del mismo, sino que contenían numerosas disposiciones relativas a las Audiencias de Indias, su jurisdicción y el tratamiento y cuidado de los indios. Un año más tarde, en 1543, por iniciativa del Consejo, se añadieron seis disposiciones adicionales. ${ }^{3}$ Los primeros nueve capítulos se dedicaban exclusivamente a los aspectos internos de la institución. Subsidiariamente, para la resolución de aquellos asuntos que no estuvieran regulados por las nuevas ordenanzas, se debían observar las del Consejo de Castilla. ${ }^{4}$

Apenas transcurridas tres décadas desde la formación de esta primera normativa, y también como consecuencia de otra visita, esta vez realizada por el licenciado Ovando, se promulgaron las ordenanzas del Consejo de Indias de 1571. Estas culminaban el proceso de separación de este tribunal respecto del Consejo de Castilla, y consagraba la autonomía del joven Consejo de Indias en lo relativo a su propio gobierno y funcionamiento. Tras unas primeras leyes generales sobre el trabajo del Consejo, se regulaban las obligaciones, derechos y privilegios de cada uno de los miembros que lo componían, comenzando por el presidente y terminando por el cosmógrafo-cronista.

\footnotetext{
2 Ayala, Manuel José de: Notas a la Recopilación de Indias, Madrid, 1946, T. II.

3 Schäfer, Ernesto: El Consejo Real y Supremo de las Indias, Sevilla, 1935, T. I, págs. 66-70.

4 Muro Orejón, Antonio: "Las Ordenanzas de 1571 del Real y Supremo Consejo de las Indias", Anuario de Estudios Americanos, XIV, Sevilla, 1957, pág. 364.
} 
Las ordenanzas de 1571 se promulgaron como parte de una futura recopilación de leyes de Indias, que no llegó a realizarse hasta finales de la siguiente centuria. Para entonces, estas ordenanzas habían sido sustituidas por otras promulgadas por Felipe IV en Madrid, el 1 de agosto de 1636. La elaboración de este cuerpo legal parece que vino propiciada por la falta de ejemplares impresos de las antiguas ordenanzas que, según era costumbre, se solían entregar a los nuevos consejeros. ${ }^{5}$ Es de suponer, sin embargo, que la existencia de numerosas disposiciones dictadas desde 1571 debió pesar, todavía con mayor fuerza, en el ánimo del Consejo de Indias a la hora de impulsar la formación y promulgación de unas nuevas que recogiesen esta normativa. Como últimamente ha demostrado el profesor Sánchez Bella, la formación de las ordenanzas del Consejo de Indias de 1636 fue realizada por el licenciado Antonio de León Pinelo. Éstas formaban parte de una recopilación más amplia de leyes de Indias, sustancialmente coincidente con la de $1680 .{ }^{6}$ Las ordenanzas de 1636 han sido estudiadas con acierto por Schäfer, que destaca, entre otras cosas, su gran extensión respecto a las anteriores, por lo que no pueden ser entendidas como una mera edición de las antiguas. Como dato significativo señala este autor que, frente a los 122 capítulos que contienen las ordenanzas de 1571, las de 1636 comprenden 245, observándose este crecimiento normativo especialmente en las leyes relativas a las secretarías del Consejo y a la contaduría de Indias, que experimentaron un importante desarrollo en este tiempo. ${ }^{7}$ Cuando por fin se promulgó en 1680 la Recopilación de Leyes de Indias, se incorporaron en su libro II las de 1636.

\section{La formación de las nuevas ordenanzas}

\section{El comienzo de los trabajos: algunas dudas preliminares}

A finales del siglo XVIII, el Consejo de Indias se seguía gobernando a partir de las ordenanzas dictadas siglo y medio antes por Felipe IV. Sin embargo, el paso del tiempo había vaciado o modificado sustancialmente el contenido de muchas de estas disposiciones. En este aspecto, la situación

5 Schäfer: El Consejo Real..., T. I, págs. 235 y 236.

6 Sánchez Bella, Ismael: "Hallazgo de la 'Recopilación de las Indias' de León Pinelo", en Derecho Indiano. Estudios, T. II, Pamplona, 1991, pág. 26.

7 Schäfer: El Consejo Real..., T. I, págs. 234-244. 
de otros Consejos de la monarquía era similar o incluso peor. Así, por ejemplo, el Consejo de Castilla carecía de una colección formal de normas relativas a su régimen interno, hallándose éstas dispersas por todo el ordenamiento legal. ${ }^{8}$ Para remediar esta situación, que, como hemos dicho, afectaba a la generalidad de los Consejos, la Junta de Estado propuso en su instrucción reservada "renovar las instrucciones con que se gobiernan los Consejos y Cámaras, acomodándolas a los tiempos presentes y mejorándolas en cuanto sea posible, oyendo para ello a los ministros más doctos, activos y celosos". ${ }^{9}$ De acuerdo con el dictamen de la Junta de Estado, Carlos IV promulgó una real orden, con fecha de 19 de noviembre de 1790, en la que encomendaba al Consejo de Indias el nombramiento de una junta de ministros que procedieran a revisar y actualizar las ordenanzas de este tribunal. Una vez realizado este trabajo, la citada junta debía remitir las ordenanzas al rey, con el correspondiente dictamen del gobernador del Consejo, para que una vez aprobadas, fueran enviadas a la imprenta. ${ }^{10}$

En cumplimiento de esta orden, don Francisco Moñino, gobernador del Consejo, nombró a los consejeros don Rafael Antúnez, don Jorge Escovedo, don José García de León y Pizarro y don Manuel de Ayala para que formaran dicha Junta encargada de actualizar las ordenanzas de 1636, suprimiendo lo que estuviese derogado y añadiendo o modificando lo que fuera pertinente, de acuerdo con las disposiciones que se habían dictado con posterioridad, o con la práctica que se seguía en el Consejo. Para el cumplimiento de esta labor, la Junta solicitó de las Secretarías del Consejo de Indias que se le remitiesen todos los documentos relativos a su encargo. Como segunda medida, trazaron un plan de trabajo y distribuyeron los títulos de que se componían las ordenanzas entre los distintos ministros, para que cada uno por separado los estudiase y propusiese lo que juzgase conveniente. Sobre este trabajo se debatiría en las sucesivas juntas. Todo parece indicar que los consejeros se aplicaron con diligencia a su tarea. ${ }^{11}$ Sin embargo, ya en la primera reunión, que celebraron el 19 de diciembre de 1790, se propuso que el presidente de la Junta, don Rafael Antúnez, diri-

8 AGI, Indiferente General, 885, Real orden de 19 de noviembre de 1790; recogida también en la Novísima Recopilación, lib. IV, tit. III, ley V. pág. 220 .

9 Ferrer del Río, Antonio: Obras originales del Conde de Floridablanca, Madrid, 1867,

10 AGI, Indiferente General, 885. Real orden de 19 de noviembre de 1790.

11 AGI, Indiferente General, 885. Informe de la Junta de ministros encargada de formar las nuevas ordenanzas del Consejo de Indias, dirigido al marqués de Bajamar, gobernador del Consejo de Indias, 13 de mayo de 1802 . 
giera una consulta al gobernador del Consejo para que éste se la hiciese presente al rey, con el fin de que se resolvieran algunas dudas que se les habían planteado e imposibilitaban, a juicio de los consejeros, seguir con este trabajo.

En ejecución del acuerdo de la primera reunión, el presidente remitió un oficio con fecha de 25 de diciembre de ese mismo año, dirigido al gobernador del Consejo, en el que le hacía partícipe de los interrogantes que habían paralizado su trabajo. Como cuestión previa, y demostrando una fina sensibilidad jurídica, Antúnez planteaba que la adecuación de las ordenanzas a los tiempos presentes conllevaba necesariamente la alteración o revocación de algunas de las leyes de la Recopilación, lo que contravenía lo dispuesto en la propia Recopilación al no seguirse los trámites establecidos por ésta para crear o revocar leyes. A continuación exponía el primero de los problemas que habían suspendido la actividad de la Junta, y que se refería a las competencias del Consejo, cuestión sumamente espinosa ${ }^{12}$ que había sido fuente continua de conflictos a lo largo de ese siglo. Recordaba Antúnez que, según dos decretos de fecha 20 de enero y 11 de septiembre de 1717, se habían reducido las competencias del Consejo de Indias a los negocios contenciosos y de mera justicia. Además, se le había despojado a este tribunal de la facultad de expedir despachos u otras disposiciones de gobierno y se le había apartado del conocimiento de los asuntos de hacienda, guerra, navegación y comercio, así como de la provisión de empleos y cargos. Lo dispuesto en estos dos decretos — continuaba el presidente de la Junta- había sido revalidado por dos cédulas de 18 de Mayo de 1747 y 3 de agosto de 1748. Siendo esto así, reconocía el propio Antúnez que la práctica seguida por el Consejo de Indias hasta ese momento contradecía las disposiciones legales que acababa de citar, por lo que la Junta no sabía a qué atenerse. Esta contravención de lo dispuesto en los decretos de 1717, 1747 y 1748 se manifestaba especialmente en los asun-

12 AGI, Indiferente General, 885. Anotación de un oficial de la Secretaría de Gracia y Justicia a continuación del extracto de la consulta de don Rafael Antúnez. En ella se afirma que los interrogantes planteados por la Junta de ministros "son los puntos más delicados, más espinosos, y más expuestos a choques entre los Ministerios de Indias. Más delicados, porque son sobre la autoridad y facultades del Consejo que en el día no están bien fixadas, por que a la verdad son varias e inconstantes las declaraciones sobre estos particulares, y hay en el archivo de esta Secretaría una multitud de expedientes en orden a cada uno que amedrentan. Mas escabrosos porque se rozan los puntos de las facultades del Consejo con las que los Ministros exercen y han exercido especialmente en este siglo. (...). Mas expuestos a choques por lo que acaba de decirse y porque cada Ministro por lo que toca a su Departamento, se opondrá a que el Consejo hiciese algunas declaraciones que coartasen tal vez las prerrogativas que disfrutan o exercen por el beneplacito de S.M. y no estan sugetas a reglas". 
tos de comisos, de los que conocía el Consejo tanto en sala de Justicia como en sala de Gobierno. Asimismo, las casas de moneda se hallaban sujetas a la jurisdicción del Consejo que, además, resolvía en apelación las testamentarías y abintestatos de los militares que morían en Indias, así como los recursos de nulidad e injusticia notoria de los negocios ejecutoriados en la Audiencia de la Casa de Contratación, relativos al comercio con las Indias.

La segunda cuestión que se planteaba hacía referencia al plan económico de las secretarías del Consejo, regulado fundamentalmente por un real decreto de 20 de enero de 1717 que, según estos ministros, no se hallaba en práctica en muchos de sus apartados. En tercer lugar se encontraba el problema de la contaduría, que no sólo era competente en los asuntos de la hacienda indiana, vedados al Consejo, sino que se entendía directamente con la vía reservada, por lo que la Junta desconocía las disposiciones que para su funcionamiento se podían haber dictado por este conducto. En cuarto lugar se consultaba si en las ordenanzas que tratasen del gobierno interior del Consejo debía recogerse la división de negocios entre el propio Consejo y la Cámara de Indias, pues cuando se promulgaron las ordenanzas de 1636, este órgano no existía. Por último, la Junta suplicaba que se concediese a su presidente la facultad de solicitar de Sevilla cuantos papeles necesitase para la realización del encargo que se le había encomendado.

La consulta de la Junta, una vez resuelta por don Antonio Porlier, marqués de Bajamar, fue devuelta al Consejo para que éste le transmitiese la resolución adoptada. Así, mediante oficio de 26 de octubre de 1791, el decano del Consejo hizo partícipe a los ministros de la Junta de la decisión tomada por el marqués de Bajamar en relación a la consulta que habían formulado. En su contestación, el secretario de Gracia y Justicia aclaraba que el encargo que había recibido la Junta no iba encaminado a la formación de unas nuevas ordenanzas, sino a

"recoger en un quaderno las reglas, observancias y obligaciones del presidente, Governador, y Ministros de la tabla y asimismo de todos los subalternos, y dependientes del Consejo, sus oficinas, archivos, arreglo de oras, trabajo de los oficiales, $\mathrm{y}$ en una palabra a prevenir y decretar todo quanto conduce a la disciplina interna, y externa del tribunal".

Se pretendía, de esta manera, que todo el personal que trabajaba en el Consejo de Indias, desde su presidente hasta el último subalterno, conociese con certeza sus respectivas obligaciones. Aun cuando el marqués de 
Bajamar afirmaba al comienzo de su dictamen que el trabajo de la Junta no debía traducirse en la formación de unas nuevas ordenanzas, en otro lugar de este mismo escrito ordena que "las nuevas ordenanzas que se formen"13 debían remitirse a las leyes de Indias, "citandolas oportunamente sin entrar en interpretaciones, extensiones, ni alteraciones de ellas". Por otra parte, del estudio de las actas de las sesiones que realizó la Junta se desprende que el objetivo final de ésta era realmente la formación de unas nuevas ordenanzas, partiendo del estudio crítico de las anteriores de 1636, incorporadas a la Recopilación de 1680, y de la normativa dictada con posterioridad a esta fecha, así como de la experiencia acumulada en todos estos años. Por último, Porlier animaba a la Junta a solicitar de Sevilla cuantos papeles necesitase para la realización de su trabajo. ${ }^{14} \mathrm{El}$ dictamen del marqués de Bajamar fue aprobado por la Junta Suprema de Estado, mediante acuerdo de fecha 10 de octubre de 1791, en el que se ordenaba que se remitiese la orden consiguiente al gobernador del Consejo de Indias para que éste la comunicase a la Junta.

\section{Desarrollo de las sesiones de la Junta de ministros}

Una vez resueltos los interrogantes que habían paralizado momentáneamente el trabajo de los ministros del Consejo, la Junta reanudó sus sesiones. Entre el 30 de octubre de 1791 y el 3 de febrero de 1792, los consejeros se reunieron en cuatro ocasiones para trazar las líneas maestras del plan de trabajo que pensaban seguir. Así, en la primera de estas juntas se acordó el cotejo de las antiguas ordenanzas de 1636, con los títulos de las leyes de la Recopilación de 1680, con el fin de comprobar cuáles de aquéllas se hallaban contenidas en éstas. A la vez debían revisarse todos los autos acordados posteriores del Consejo, que tratasen de los mismos asuntos que las ordenanzas. Para este cometido, se distribuyeron los distintos capítulos entre los ministros. ${ }^{15}$ En la cuarta junta celebrada desde que comenzaran los trabajos, que tuvo lugar el 7 de enero de 1792, se decidió, siguiendo con el plan de organización del trabajo, que hasta la próxima

13 El subrayado es nuestro.

14 AGI, Indiferente General, 885. Contestación a la Junta, anotada al margen del extracto formado por la Secretaría del Despacho de Gracia y Justicia.

15 Como ya indicamos en la nota primera de este trabajo, el contenido de las juntas realizadas por los consejeros encargados de actualizar las ordenanzas del Consejo, se puede consultar en AGI, Indiferente General, 886. 
reunión cada uno de los ministros analizase las ordenanzas y leyes relativas al capítulo primero del Consejo, anotando lo que se debía suprimir, añadir o conservar, conforme a las resoluciones que desde entonces se habían dictado. Los consejeros resolvieron también que el vocal de la Junta más antiguo solicitase de la secretaría de lo Indiferente copia de los decretos de establecimiento, supresión y renovación de la Cámara de Indias. Esta documentación fue aportada en la siguiente sesión, donde se leyeron y analizaron estos decretos. Con todo este material y el trabajo previo realizado por cada uno de los ministros, la Junta se encontraba ya en condiciones de afrontar el arduo cometido para cuya realización había sido constituida.

En efecto, en las tres sesiones siguientes, que tuvieron lugar entre el 24 de febrero y el 9 de marzo de 1792, se comenzó a redactar el borrador de las nuevas ordenanzas, ${ }^{16}$ finalizando la elaboración del capítulo primero sobre el Consejo en la última de estas reuniones. Ante la ausencia de don Rafael Antúnez, presidente de la Junta, el vocal más antiguo, don Jorge Escovedo, ocupó su lugar en la siguiente reunión, por indicación del decano del Consejo de Indias. Escovedo era, además, el depositario de todos los papeles de la Junta. En esta sesión se decidió modificar la ordenanza número $15^{17}$ pues "convenía limitar la facultad que se da al que presida la sala para llamar quien decida en igualdad de votos, añadiendo sea sin esperar el ministro de la sala que aquel día haya faltado, y en el acto se llame al mas moderno de otra sala de Gobierno". Se rectificaron también algunos de los acuerdos adoptados en anteriores sesiones, relativos a la supresión de algunas ordenanzas, como la $23^{18}$ y la $26,{ }^{19}$ que ahora la Junta juzgaba que debían continuar en vigor. Se decidió asimismo suprimir parcialmente la

16 En el Archivo de Indias no hemos podido localizar este borrador al que se refiere la Junta. Sin duda, su localización sería de enorme interés para conocer el trabajo de estos consejeros.

17 La ordenanza número 15 mandaba que en caso de igualdad de votos para resolver negocios de gobernación y gracia se debía esperar al consejero o consejeros que no hubieran acudido aquel día. Si aún así no se deshacía el empate, se debía consultar al rey. En la práctica parece ser que el presidente llamaba a otro ministro de otra sala para que solucionase con su voto el conflicto.

18 La ordenanza 23 disponía que el primer lunes de cada mes se informase al rey de todos los asuntos pendientes de consulta, y si hubiese alguno urgente lo consultase el presidente del Consejo personalmente. Según Manuel José de Ayala esta ordenanza, que se correspondía con la ley 23, tit. II, lib. II de la Recopilación de 1680, no estaba "en uso, ni en memoria de que de 50 años a esta parte se haya practicado; pero no por el no uso se entiende derogada". Ayala: Notas ..., pág. 41.

19 Establecía que en el Consejo debían existir libros de acuerdos y consultas de inventarios, descripciones y bulas. Comenta Manuel José de Ayala a este respecto que "con notable sentimiento han manifestado algunos Ministros la falta de observancia de ella, viendose en algunas votaciones discordes, sin libro de acuerdo en que sentar los votos, ni los demás libros para instruirse en el acierto de las resoluciones en los negocios”. Ibídem, pág. 42. 
ordenanza $27,{ }^{20}$ dejando en vigor sólo lo referente a leer con preferencia las cartas que venían de Indias. Los vocales pasaron a continuación a examinar los autos acordados de este capítulo, sugiriendo que algunos de estos autos fueran insertados en distintos capítulos de las ordenanzas, y añadiendo pequeñas correcciones en otros. El examen de los autos del Consejo concluyó en la siguiente sesión, celebrada el 18 de mayo de 1792.

En la siguiente junta, que tuvo lugar justo una semana después, se leyó de nuevo el título del Consejo y se emplazó a los consejeros para que en la próxima sesión sugiriesen las oportunas reformas. Ésta tuvo lugar el día 8 de junio de 1792. En ella la Junta acordó introducir algunas modificaciones que agilizasen el funcionamiento interno del Consejo. Así, se resolvió no

"embarazar el Consejo Pleno, ni llevar a él las incidencias que muchas veces ocurren de expedientes tratados, o pendientes en tres salas, pues quando pudiesen separarse, y su gravedad no exija correr con el principal, siguiesen su curso natural, para que no se entorpeciesen, y dilatasen, ni el Consejo Pleno se ocupase en lo que no lo pidiese".

En esta misma línea agilizadora del trabajo del Consejo, se proponía que, no existiendo expedientes para despachar en una sala, se tomasen de las otras. Se sugería también que, cuando faltasen ministros en alguna de las salas, el que presidiese la sala primera los nombrase, comenzando por los consejeros más modernos. Asimismo, los vocales resolvieron que en las votaciones que tuvieran lugar en Consejo de tres salas, faltando ministros, bastasen cinco votos, para no dilatar excesivamente el despacho de los asuntos. También se debía modificar lo relativo al conocimiento del Consejo de los bienes de difuntos, de conformidad con lo dispuesto en los decretos de extinción de la Audiencia de Cádiz. ${ }^{21}$ En la decimotercera sesión, celebrada el

20 Esta ordenanza, que se correspondía con la ley del mismo número del libro II del título II de la Recopilación de Indias, establecía que "el inventariar y leer cartas de Indias, se prefiera a otros negocios, y se vaya luego respondiendo a ellas", según se lee en el epígrafe de la citada ley. Mediante decreto de 27 de diciembre de 1738 dispuso Felipe V, que los cajones con el correo de América se abriesen en una sala del Consejo por un ministro designado por el presidente, gobernador o decano, asistido de los secretarios y del escribano de cámara. Esta medida venía a cortar algunos abusos que se habían introducido cuando se abría el correo en Consejo pleno y los ministros pedían sus cartas y las de sus conocidos. El rey pretendía además, que la recepción del correo no bloquease inútilmente el trabajo de todo el Consejo. Ayala: Notas..., págs. 42 y 43.

21 AGI, Indiferente General, 869 B. Mediante decreto de 18 de Junio de 1790, el rey extinguió la secular Audiencia y Casa de Contratación de las Indias. En este decreto se trasladaba al Consejo de Indias "el conocimiento y adjudicación a los legítimos interesados, de los caudales de bienes de difuntos que se remiten de América". La contabilidad de éstos dependería, a su vez, de la Contaduría General del Consejo. 
siguiente 22 de junio, la Junta decidió eliminar algunas trabas legales que impedían el diligente funcionamiento de la sala de Justicia. En este sentido, se propuso que "se acusase solo una reveldía y no tres", así como que se suprimiese del procedimiento judicial la fase de pedimentos de conclusion, dándose por conclusos los autos sin necesidad de que lo solicitasen las partes.

Siguiendo el orden sistemático de las ordenanzas, los vocales comenzaron, en esta misma sesión, el examen de las disposiciones relativas al presidente del Consejo, que concluiría en la siguiente reunión. La primera ordenanza de este título se refería a la asistencia del presidente al Consejo por la mañana y por la tarde. A este respecto, entendía la Junta que se debía reducir a sólo las mañanas. En la siguiente ordenanza, la número $70{ }^{22} \mathrm{se}$ debía aclarar que, aunque correspondía al presidente velar por el cumplimiento de las resoluciones del Consejo, ello no impedía que uno de los ministros recordase cada mañana los asuntos resueltos y los pendientes. También en la ordenanza $71^{23}$ se debía añadir que, además de las listas que en cada sala se ponían para su gobierno con los negocios que debían tratarse, el presidente o quien gobernase el Consejo debía poseer una copia para decidir los asuntos que se despacharían con preferencia. En la ordenanza 72 proponían suprimir el señalamiento que correspondía realizar al presidente para el despacho de algunos negocios que se encomendaban a determinados ministros por las tardes, los martes, jueves y sábados. El motivo principal de tal recomendación era que los expedientes de confirmaciones de oficios, breves y dispensas de poca entidad debían resolverse en la sala del ministro comisionado. La ordenanza $73^{24}$ sugerían redactarla en términos generales, precisando que el presidente, no siendo letrado, tenía voto en todos los negocios que no fueran de Justicia y entre partes. La ordenanza 77, que establecía la existencia de un consejero semanero, debía modificarse para que la semanería se distribuyese por salas, "por turno semanero de sus Ministros, a fin de que no se firme Cedula, o providencia el que no estubiese instruido del negocio, o su resolucion".

La Junta, en esta misma sesión, proponía, asimismo, que se suprimiese la ordenanza 78, que ordenaba que el consejero a quien correspondiese acu-

22 Esta ordenanza encomendaba al presidente la función de proponer al Consejo lo que considerara conveniente para el mejor gobierno de las Indias, resolver lo que se acordase y ejecutarlo.

23 Establecía que el presidente debía tener los memoriales de los negocios que se hubiesen de resolver en el Consejo, y procurar que se despachasen los asuntos de los interesados ausentes.

24 Según esta ordenanza, el presidente letrado tenía voto en los asuntos de gobierno, guerra, gracia y merced, y en las visitas y residencias, y no siendo letrado sólo en los negocios de gobierno, guerra, gracia y merced. 
diese a la Junta de competencias, por no acomodarse a los últimos decretos que se habían dictado para dirimir las cuestiones de competencias entre los Consejos. ${ }^{25}$ Además, debían mantenerse como hasta ese momento las ordenanzas 76, 79, 80, 81 y 82. En la siguiente sesión, celebrada el 6 de Julio de 1792, se continuó y concluyó el examen de las ordenanzas relativas a la figura del presidente. Así, se resolvió omitir la ordenanza 83, en virtud de la cual, el juez de cobranzas del Consejo debía remitir las de Sevilla a un juez letrado de la Casa, y las de otras partes a los jueces ordinarios. Respecto a los autos acordados, apenas se modificaron, limitándose las propuestas de la Junta al emplazamiento en otros títulos de algunos de ellos.

Una vez finalizado el análisis de las ordenanzas que se referían al presidente, y antes de comenzar con el estudio del título de gran canciller, la Junta se detuvo en el examen de diversas cuestiones. Así, en esta junta, que era la decimoquinta desde que comenzaran los trabajos, se debatió acerca del turno de los relatores, según el reparto de negocios dispuesto por los gobernadores, y las quejas que al respecto habían presentado algunos relatores. Se decidió dejar el estudio de este asunto para más tarde. Se acordó, asimismo, que en la ordenanza 11 que versaba sobre el Consejo de tres salas, se tuviera presente que los negocios extraordinarios que la sala correspondiente remitía a las otras, debían ser de gravedad. La Junta resolvió, también, que se formaran las ordenanzas necesarias para el recibimiento por parte de los subalternos del presidente y consejeros. Por lo que se refiere al título del gran canciller, la Junta llamó la atención sobre el hecho de que este cargo había sido extinguido, careciendo, por tanto de sentido su regulación en las ordenanzas del Consejo. ${ }^{26}$

25 Mediante decreto de 18 de octubre de 1722, se ordenó que para la resolución de competencias entre los Consejos, se formase una junta de cinco ministros, dos por cada Consejo, y el quinto nombrado por el rey a petición de los respectivos presidentes o gobernadores de los Consejos en discordia. Asimismo, se establecía que antes de publicar la decisión debía ser comunicada al rey. Por otra parte, mediante real orden de 17 de marzo de 1789 se comunicaba al Consejo de Indias, que la resolución de las competencias entre cualesquiera jurisdicción debía resolverse por acuerdo de los fiscales de los respectivos Consejos. En caso de que éstos no llegaran a un acuerdo, se pondría en conocimiento de las respectivas Secretarías de Estado y del Despacho que lo resolverían en su Junta o lo remitirían a la Junta de Competencias, nombrándose un quinto ministro. Ayala: Notas..., págs. 80 y 81.

26 AGI, Indiferente General, 863. Título de gran canciller y registrador de las Indias, expedido a favor del duque de Alba, 9 de febrero de 1794. El oficio de gran canciller y registrador mayor de las Indias fue incorporado a la Corona por resolución real publicada en el Consejo de Indias el 22 de diciembre de 1776, según se desprende de un informe elaborado por don Tomás Ortiz de Landázuri, el 28 de enero de 1777. Hay que señalar además que, a resultas de una consulta del Consejo de Indias de 28 de septiembre de 1793, resolvió el rey restituir a la Casa del conde duque de Olivares el citado oficio, en los mismos términos en que le fue concedido a perpetuidad, el 23 de julio de 1623 . 
En esta misma sesión, la Junta comenzó el estudio de la regulación que las ordenanzas hacían de los fiscales y sus agentes, limitando las posibles modificaciones al sueldo que debían percibir. Así, los consejeros proponían que en la ordenanza $111^{27}$ se expresase el aumento concedido por el último real decreto, ${ }^{28} \mathrm{y}$ se suprimiese la ordenanza 112 por haber variado el método de pago de sueldos. ${ }^{29}$

En la siguiente Junta, que se celebró el 17 de agosto de 1792, se examinó la ordenanza 113, relativa a los agentes fiscales. Se acordó a este respecto, que se pidiese a la Secretaría el decreto en que se aumentaba a cuatro el número de agentes, y se fijaban sus sueldos. Estos extremos, según expone la Junta, habían sido determinados por una real orden de 18 de octubre de 1791, que no hemos podido localizar. En esta misma junta de 17 de agosto, se abordó también el análisis del título relativo a los secretarios del Consejo. La primera ordenanza de este título, número $114,{ }^{30}$ debía ser actualizada con arreglo a la planta que presentaban las Secretarías en esos años de finales del siglo XVIII. ${ }^{31}$ Asimismo, se proponía la actualización de la ordenanza 115, que se refería a la división geográfica de las competencias de los dos secretarios, omitiendo los tribunales que ya no existían y añadiendo los nuevos que se habían creado. Sin embargo, la Junta sugería que se delimitasen en general los territorios: por un lado Nueva España y por el otro Perú. ${ }^{32} \mathrm{La}$

27 Esta ordenanza disponía que el fiscal del Consejo (en este caso los fiscales) debía percibir el mismo salario que los consejeros, y ocupar el primer lugar después de ellos.

28 AGI, Indiferente General, 860. Decreto de 29 de julio de 1773. Entre otras cosas, igualó el salario de los fiscales del Consejo de Indias con el que percibían los fiscales del Consejo de Castilla, esto es, 55.000 reales de vellón anuales, cantidad que permaneció invariable hasta 1808 .

29 Esta ordenanza establecía que para que el fiscal del Consejo cobrase su salario debía presentar una certificación del secretario más antiguo que acreditase que había llevado cada lunes al Consejo una relación de los pleitos fiscales que estuviesen pendientes. Comenta Manuel José de Ayala al respecto, que esta ordenanza "pide total reforma, porque también estos Ministros, y los demas del Consejo son pagados de sus sueldos por la Tesorería General, y el Pagador, Receptor, ni Tesorero del Tribunal, cuyos oficios, variados en los nombres y substancia, en nada de esto intervienen. Las Relaciones y Memorial de los pleitos que estan pendientes en su poder — continúa Ayala—, no avisan de ello los Lunes, porque estas Relaciones de todos los negocios que han pasado a su poder para responder y oir sus dictamenes, las forman sus respectivos Secretarios cada mes, con fecha de él, y año en que se les pasó, y las presentan a cada Sala del Consejo". Ayala: Notas..., págs. 102 y 103.

30 Esta ordenanza establecía la existencia de dos secretarios, cada uno con dos oficiales mayores y dos segundos.

31 La cifra oficial de los oficiales que, según un decreto de 4 de enero de 1720, en vigor hasta 1808, debían componer las Secretarías era de ocho: un oficial primero o mayor, dos segundos, dos terceros, y tres aspirantes. Sin embargo, lo habitual a lo largo del siglo XVIII fue que entre diez y doce oficiales trabajaran en cada una de las Secretarías del Consejo de Indias. Bernard, Gildas: Le Secrétariat d'Etat et le Conseil Espagnol des Indes (1700-1808), Geneve, 1972, págs. 85 y 86.

32 Comentando esta ordenanza, apunta Manuel José de Ayala que debiera quitarse la referencia a las Audiencias de Panamá y Buenos Aires, pues fueron extinguidas en su día. Ayala: Notas..., pág. 106. 
ordenanza 116, en opinión de la Junta, debía ser suprimida en su casi totalidad, quedando tan sólo en vigor lo relativo al refrendo por los secretarios de los despachos de Cruzada. ${ }^{33}$ Para el examen de la ordenanza 117, a tenor de la cual los negocios comunes o neutrales debían despacharse por el secretario más antiguo, la Junta decidió que se solicitase a la Secretaría "razón de la actual división de negocios de ambas, y agregación de lo indiferente". ${ }^{34}$

Continuando con el repaso de las disposiciones relativas a los secretarios, la Junta decidió que la ordenanza 119 fuera corregida parcialmente y adaptada a la práctica que se seguía en el Consejo, ${ }^{35}$ según la cual cuando faltaba algún secretario, el otro publicaba lo concerniente a las dos Secretarías, pero el oficial mayor del secretario ausente pasaba a despachar en el Consejo. ${ }^{36}$ Igualmente, la ordenanza 120 debía ser adaptada para que los consejeros asistieran a los litigantes y pretendientes en las oficinas y no en sus casas. ${ }^{37}$ A continuación, la Junta decidió que algunas ordenanzas continuasen sin variación, y otras fueran suprimidas, por coincidir con algunas leyes de la Recopilación de $1680{ }^{38}$ lo cual no deja de causarnos extrañeza por cuanto es sobradamente conocido que las ordenanzas de 1636, en su totalidad, fueron incorporadas a la Recopilación de 1680.

El día 31 de agosto de 1792, la Junta celebró su decimoséptima sesión. Continuando con el estudio de las ordenanzas relativas a los secretarios, y al igual que en la anterior junta, los consejeros decidieron omitir una serie de

33 Según esta ordenanza era competencia del secretario del Perú los despachos de la Armada de la carrera y flotas de Tierra Firme y Perú, y del secretario de Nueva España los de Nueva España y Honduras. El contenido de esta ordenanza quedó derogado por los decretos de 20 de enero y 11 de septiembre de 1717, que despojaron al Consejo de Indias de estas competencias en favor de la Secretaría de Estado y del Despacho de Indias. Ayala: Notas..., pág. 107.

34 Precisa Manuel José de Ayala en sus comentarios a la Recopilación de 1680, que con ocasión de haberse aumentado el número de plazas togadas del Consejo a catorce, y formado tres salas, el rey, mediante decreto de 6 de junio de 1776, resolvió que el negociado de lo Indiferente quedase fijo en la Secretaría del Perú. Ayala: Notas..., pág. 107.

35 La ordenanza 119 establecía que cuando algún secretario estuviese impedido, el otro debía suplirlo, no entrando ningún oficial en el Consejo, salvo en el caso de que faltaran los dos secretarios.

36 A consulta del gran canciller del Consejo, de 18 de agosto de 1776, resolvió el rey, que cuando los dos secretarios estuviesen trabajando en la primera de las tres salas, o resultaren ausentes o enfermos, los oficiales mayores debían sustituirlos en la segunda y en la tercera sala, y en su defecto, los oficiales segundos. Por tanto, se les debía conferir título de secretarios del rey, para que pudieran dar fe de lo que ocurriera en las respectivas salas. Ayala: Notas..., pág. 107.

37 Según esta ordenanza, los secretarios debían asistir en sus casas el tiempo que no estuviesen en el Consejo. A este respecto, Manuel José de Ayala comenta que "estando hasta la una del día en sus Secretarías, como lo están los demas de los otros Consejos, basta, y no hay necesidad de que asistan de ordinario en sus casas, porque han de tener las tardes de descanso". Ayala: Notas..., pág. 108.

38 En concreto, los consejeros propusieron suprimir, por este motivo, las ordenanzas 125, 126, $127,129,130$ y 131 . 
ordenanzas por considerar que se correspondían con otras tantas leyes de la Recopilación ${ }^{39}$ En la siguiente junta, que tuvo lugar el 7 de septiembre de ese mismo año, se comenzó el examen de los autos acordados del título relativo a los secretarios. La Junta propuso que el auto número 15, que establecía que los secretarios tenían obligación de firmar y rubricar todos los papeles e inventarios del Consejo que "entraren en su poder", se añadiese a la ordenanza $121 .{ }^{40}$ Asimismo, el auto número 29 , debía ser transformado en ordenanza. ${ }^{41}$ Por otra parte, se dejaba en suspenso la corrección del auto 98 que establecía una preferencia de los oficiales mayores sobre los contadores en los actos públicos, por cuanto aquéllos gozaban de la condición de secretarios del rey. Además, la Junta disponía que se solicitasen las declaraciones hechas al respecto por el rey en tiempos de los contadores Tomás Ortiz de Landázuri y Francisco Machado. Al mismo tiempo, la Junta mostraba sus reservas acerca de su competencia para regular este punto.

El examen de los autos acordados del título relativo a los secretarios se concluyó en la siguiente junta, de fecha 22 de ese mismo mes de septiembre. Los consejeros resolvieron que los citados autos se completasen con una serie de disposiciones tendentes a mejorar la gestión y el control de las Secretarías. En este sentido, debía añadirse a los autos acordados, que cada oficial semanalmente presentaría "una lista a su Gefe de los expedientes de su mesa, y estado, con fecha del dia que entraron en ella, e igualmente lista de las Cedulas, Despachos, o Cartas Acordadas que expida por ella, y fecha de los Acuerdos en que se mandaron librar, del mismo modo razon de las consultas pendientes, y que deban hacerse". Asimismo, las Secretarías no debían entregar a las partes "Cedulas, Despachos, o Cartas de Ynformes, solo los Titulos de empleos, o Comisiones que las mismas hayan de exercer, y se remitan en derechura". En lo relativo a los aranceles de las Secretarías, la Junta se abstuvo de realizar recomendación alguna, por cuanto ya existía una comisión encargada de su formación. Por otra parte, se juzgó oportuno averiguar el método que se empleaba en las Secretarías en la formación de extractos de los expedientes, y discernir entonces los que corresponderían a las Secretarías y a los relatores, teniendo en cuenta lo dispuesto en la ordenanza $158 .{ }^{42}$

39 Estas ordenanzas fueron la 133, y de la 136 a la 165.

40 Esta ordenanza establecía que los papeles debían ser entregados a los secretarios mediante inventario, a través del cual se les pediría luego cuenta de ellos.

41 Este auto ordenaba que cuando se le recordara al rey una consulta se le debía remitir una copia de ella.

42 Según esta ordenanza los secretarios debían sacar una relación de todo lo que se pidiese o escribiese al rey, ordenándolo en un libro por materias y lugares. 
En la vigésima sesión, que se celebró el siguiente 5 de octubre, la Junta comenzó el estudio de las ordenanzas relativas a los relatores, resaltando la conveniencia de que se nombrara un tercer relator "por la falta de tiempo para formar extractos y Memoriales". ${ }^{43}$ Sin embargo, la Junta estimaba que este tipo de propuestas era ajeno a sus competencias, por lo que dejó de lado este asunto para proponerlo en su día junto con otras dudas que se le planteasen. Sobre el turno de los relatores se había tratado ya, brevemente, en la junta de 20 de julio de ese mismo año, cuando se examinaron las ordenanzas relativas al gran canciller. En aquella reunión se decidió posponer el tema hasta que se tratase de los relatores en general. Llegado el momento de abordar este controvertido asunto, que había originado una consulta de la sala de Justicia del Consejo al rey, ${ }^{44}$ la Junta resolvió que "se insertase en una o mas ordenanzas de este Titulo la division de negocios en las quatro partes de oficio, y Pobres, y ademas de sus quatro turnos se formasen otros dos de Residencias". ${ }^{45}$ También se trató en esta junta de los aranceles de los relatores. Sin embargo, no se adoptó ningún acuerdo al respecto, dada la existencia de una comisión encargada de su formación.

El 13 de octubre de 1792 la Junta debatió sobre los escribanos de cámara. Los consejeros resolvieron que se redujeran las catorce ordenanzas que regulaban este oficio a una sola que se limitase a ordenar la observancia de las leyes de este título de la Recopilación de 1680. También se acordó solicitar del Consejo los acuerdos y reales decretos relativos a la obligación del escribano de cámara de dar parte, en los recursos de segunda suplicación y de injusticia notoria, de haber realizado las partes los preceptivos depósitos, con el fin de incorporar estas disposiciones a las ordenanzas.

En la siguiente sesión, el consejero Escovedo hizo partícipe al resto de los vocales, de una conversación que había mantenido con el gobernador del

43 Es preciso apuntar que desde 1715 hasta el final del reinado de Carlos IV, el número de relatores del Consejo de Indias se mantuvo en tres. Bernard: Le Secrétariat..., pág. 234.

44 La tensión existente entre los relatores venía ocasionada por las protestas de algunos de ellos, que se sentían perjudicados en la distribución de expedientes que realizaba la Secretaría de la Presidencia. Como es sabido, los relatores percibían unos derechos en función del número de hojas de los expedientes que relataban. Por ello, de una correcta o incorrecta distribución de expedientes se derivaban beneficios o perjuicios económicos para aquéllos.

45 AGI, Indiferente General, 860. Acuerdo de 26 de junio de 1780. Para agilizar la tramitación de los expedientes y pleitos, y racionalizar su distribución entre los relatores, el Consejo había dispuesto, mediante dicho acuerdo, que aquéllos se dividieran en cuatro categorías: de partes, de oficio, de pobres y de residencias. Se formarían de esta manera seis turnos: $1 .^{\circ}$ Negocios de oficio y de pobres de gobierno. $2 .^{\circ}$ Negocios de parte de gobierno. $3 .^{\circ}$ Negocios de oficio y pobres de justicia. $4 .^{\circ}$ Negocios de parte de justicia. $5 .^{\circ}$ Residencias de virreyes, presidentes y principales gobernadores. $6 .{ }^{\circ}$ Residencias de gobernadores menores y ministros de menor categoría. 
Consejo sobre la conveniencia de trasladar el día de reunión de la Junta al sábado, por celebrarse los viernes Consejo pleno. No parece que hubiera oposición alguna por parte de los vocales de la Junta. A continuación, se pasó a examinar el título de los contadores, y tras comprobar la correspondencia de las ordenanzas que regulaban este cargo con las leyes respectivas de la Recopilación de 1680, se decidió, como en la anterior junta, condensar las ordenanzas de este título en una sola, que ordenase el cumplimiento de las citadas leyes. Además, se vio la conveniencia de insertar como ordenanza el auto acordado número 12, que prohibía a la contaduría dar ninguna relación sin consultar antes al Consejo. También se juzgó oportuno transformar en ordenanza la última disposición de este título, que recogía un acuerdo del Consejo de Indias de 5 de mayo de 1638. En este acuerdo se ordenaba a los contadores, entre otras cosas, que utilizasen el término "señor", para nombrar al presidente y consejeros de Indias, que comunicasen al Consejo o al consejero comisario, mediante un breve expediente, los despachos de los que tomasen razón y los reparos que hubieran puesto, que no dictasen despachos que fueran competencia de las Secretarías... En favor de las atribuciones de la contaduría, este acuerdo de 1638 reconocía a esta oficina la facultad de "hacer reparos en los despachos que ván de las dos Secretarias del Consejo", no sólo por errores de cuenta, sino también cuando contravinieran órdenes, cédulas u otros despachos anteriores, de los que se hubiere tomado razón en la misma contaduría. ${ }^{46}$ Por último, en lo que se refiere a los aranceles de los contadores se decidió esperar a que la comisión encargada de su formación se pronunciase al respecto.

En la siguiente junta, que tuvo lugar el 3 de noviembre de ese mismo año, se revisó todo lo acordado en las dos anteriores sobre la contaduría y se decidió formar una o varias ordenanzas que recogiesen lo dispuesto en los decretos de 27 de marzo y 10 de abril de $1760,{ }^{47} 10$ de noviembre de

46 Comenta Manuel José de Ayala, que este acuerdo de 5 de mayo de 1638 "se cumple y practica, excepto comunicarlo con el consejero comisario, pues lo hacen en derechura al tribunal por medio del secretario á quien corresponda el asunto". Ayala: Notas..., pág. 151.

47 AGI, Indiferente General, 990. Decreto de 27 de marzo de 1760. Realizaba una remodelación general de la planta de la contaduría y de su régimen de trabajo. Así, por lo que se refería a la composición de sus oficinas, se confirmaba en su puesto al contador general, don Felipe de Altolaguirre, con un sueldo de 50.000 reales de vellón anuales. Se nombraba, además, un oficial mayor, a quien correspondían 15.000; un oficial segundo, con 12.000; dos terceros con 10.000 cada uno; dos oficiales cuartos, ambos retribuidos con 8.000; dos quintos, con 6.000 cada uno; dos entretenidos, ambos con 3.000 y un portero del Consejo, que debía prestar sus servicios en las oficinas de la contaduría. Por otra parte, se ordenaba al Consejo y a la Cámara de Indias, que no evacuase expediente alguno en que directa o indirectamente se vieran afectados los intereses de la Hacienda real sin que precediese informe de la contaduría. Además, una vez resueltos y adoptadas las providencias oportunas, estos expedientes debían pasar a la contaduría donde se guardarían. En el mismo legajo: Decreto de 10 de abril de 1760 . Nombramiento de los sujetos que debían servir estas plazas de oficiales. 
$1751^{48}$ y 7 de febrero de $1788 .{ }^{49}$ Entrando ya en el examen de las ordenanzas relativas al receptor, la Junta las halló conformes con las leyes de la Recopilación. Asimismo, constató la inobservancia "de muchos de los puntos contenidos en dichas Leyes, y alterados otros, ó pendientes de Expedientes no resueltos". Los consejeros eran conscientes, sin embargo, de que en virtud de la real orden de 18 de octubre de 1791 no debían innovar las leyes, por lo que se decidió suspender el arreglo de este título hasta que se resolviese el alcance de sus competencias en este tema. En caso de que se les autorizase para modificar la legislación, la Junta veía la necesidad de solicitar los últimos reglamentos que se habían dictado sobre este oficio. ${ }^{50}$

También renunciaron los consejeros a modificar las ordenanzas sobre el cronista, hasta que se aclarasen las facultades de la Junta, por cuanto las disposiciones que se habían promulgado por la vía reservada sobre el método de describir la historia de Indias, así como lo último que se había regulado sobre este oficio, contradecían lo establecido en las propias ordenanzas y en las leyes de Indias. La misma resolución adoptó la Junta, al abordar el estudio de la regulación del cosmógrafo, por concurrir idénticas circunstancias. En esa misma sesión la Junta continuó con el examen del título del alguacil y sus oficiales, y concordando las ordenanzas con las leyes de la Recopilación decidió no introducir modificación alguna. Sin embargo, sí juzgó oportuno añadir un nuevo título referido a los porteros y mozos sirvientes, en el que, entre otras cosas, se incluyesen algunas reglas extraídas de las advertencias que hizo el juez de ministros, Pedro Muñoz de la Torre, a estos dependientes, el 4 de mayo de $1779 .{ }^{51}$

48 AGI, Indiferente General, 1009. Consulta del Consejo de Indias de 18 de agosto de 1773. Probablemente se refiera al decreto de 11 de Octubre de 1751 que creó la figura del contador general, permaneciendo el resto de contadores en sus empleos al servicio del primero hasta que el rey les proporcionase nuevos oficios.

49 AGI, Indiferente General, 872. Existe un error de transcripción, pues la fecha correcta del real decreto que dispuso la división de la contaduría es de 17 de febrero de 1788.

50 AGI, Indiferente General, 909. Reglamentos relativos a las funciones del tesorero y a la exacción de las penas de Cámara. El primero de ellos es de fecha 5 de noviembre de 1771 y lleva por título "Reglamento y Ordenanza de lo que se ha de obserbar para la custodia, buena administracion y mejor cuenta y razon de los caudales propios del Consejo y de los demas ramos y causas que protege". El segundo es de 24 de junio de 1798. El tercero, aprobado en 1799 modificaba parcialmente el anterior, y tenemos noticia de él a través de la obra del historiador francés Bernard: Le Secrétariat..., págs. 100 y 101.

51 AGI, Indiferente General, 829. Advertencias del juez de ministros Pedro Muñoz de la Torre, 4 de mayo de 1779. En estas advertencias o recomendaciones, Muñoz de la Torre resumía las principales obligaciones que debían observar los porteros. Así, entre otras cosas, recordaba que cada una de las salas del Consejo debía estar atendida por dos porteros de manera que cuando en una de las salas se llamase a uno de éstos, el otro debía permanecer a la puerta, cuidando de que nadie se 
Una vez la Junta hubo concluido el examen de todas las ordenanzas del Consejo, y su cotejo con las leyes y autos acordados, los vocales decidieron remitir a don Rafael Antúnez, presidente de la Junta, que ya había regresado a Madrid, los papeles con el resultado del trabajo realizado. Asimismo, se juzgó conveniente reservar la siguiente junta para tratar de los asuntos que habían quedado pendientes de resolución. En cumplimiento de estos acuerdos, los vocales se trasladaron a la posada de don Rafael Antúnez, que recibió los documentos con las propuestas. Sin embargo, dado su precario estado de salud, pasaron los años sin que convocara de nuevo a la Junta; finalmente falleció en Cádiz. Como se solía practicar en estas ocasiones, don Silvestre Collar recuperó de casa del difunto Antúnez todos sus papeles, entre los que se encontraban los trabajos de la Junta, y los remitió al gobernador del Consejo. Con fecha 18 de enero de 1802, el marqués de Bajamar, gobernador del Consejo, los devolvió de nuevo a la Junta, nombrando a los consejeros Acedo y Torres Múzquiz en sustitución de Antúnez y José García Pizarro, que también había fallecido.

Don Jorge Escovedo, nuevo presidente de la Junta, convocó a los vocales para el siguiente día 1 de febrero de 1802. Después de que cada uno se instruyera de lo actuado hasta ese momento, se leyeron todos los papeles que recogían el trabajo realizado. Concluida la lectura, se acordó que Manuel José de Ayala "formase un breve apunte, o extracto de todas las Juntas para dar una historia, o razon coordinada y seguida, en que con claridad se viese lo que ya estava travajado, como las dificultades y dudas que impedían la conclusion de este negocio". Este informe, redactado por Ayala, es el que nos ha servido de base para conocer los trabajos de la Junta encargada de la formación de las nuevas ordenanzas del Consejo de Indias. En las sucesivas reuniones, los vocales examinaron los apuntes redactados por Ayala y debatieron sobre las dificultades que impedían ter-

\footnotetext{
acercase a escuchar. Los porteros debían concurrir a sus puestos treinta minutos antes de la hora señalada a los ministros. Si por cualquier causa alguno no podía asistir, debía advertirlo al portero de estrados, para que éste lo comunicara al Juez de ministros, expresando el motivo o enfermedad. Formaba también parte del trabajo encomendado a los porteros el comunicar recados a los ministros que se hallasen indispuestos, siguiendo un turno ya establecido que comenzaba por el más moderno y excluía al portero de estrados y al de la contaduría. Lo mismo se practicaba cuando se trataba de convocar a los ministros a Juntas o cuando se les debían comunicar avisos particulares. Pedro Muñoz de la Torre recordaba también a los porteros que los recursos debían dirigirlos al juez de ministros o al decano del Consejo. Respecto a las propinas establecía que los porteros debían ponerse de acuerdo, llevando en una caja común la cuenta y razón de las propinas y emolumentos, que se repartirían al final de cada mes con la debida igualdad. Por último, les recordaba que debían obedecer al portero de estrados en todo, pues a éste correspondía ordenar los avisos y cuidar del servicio puntual de los porteros del Consejo.
} 
minar con éxito este trabajo. De esta manera, la Junta concluyó que no era posible formar las ordenanzas que se habían propuesto y decidió remitir al gobernador del Consejo un oficio con los resultados de este expediente, el informe elaborado por Manuel José de Ayala, y todos los papeles sobre este asunto, con el fin de que el marqués de Bajamar diese cuenta al rey y éste resolviera.

Ayala terminaba su escrito exponiendo algunas de las dificultades y dudas que habían encontrado en su trabajo que impedían que éste pudiera concluirse satisfactoriamente. Así, en primer lugar, señalaba que el desorden que imperaba en el Archivo de Indias retrasaría mucho la remisión de los papeles que necesitaban para concluir su misión. Lo mismo sucedería con los documentos que se solicitasen de los Consejos y Secretarías. Por otra parte, "repetidas serían las consultas con que la Junta incomodaría a los Ministerios, y de consiguiente á S.M.", por las múltiples dudas que habían surgido. A modo de ejemplo, Ayala exponía algunas de las cuestiones que se le habían planteado sobre el nombramiento de los visitadores del Consejo, a quién correspondía, su número, quién corría con los gastos... Del mismo modo, las figuras del juez de ministros o del secretario de la interpretación de lenguas, planteaban, a los ojos de la Junta, un sinfín de interrogantes difíciles de resolver. El mismo número de problemas habían surgido a la hora de examinar "las facultades, preeminencias, recivimientos, Juramentos y Ceremonias correspondientes, respectivamente, al Señor presidente, Gobernador, Gran Chanciller, y Decano del Consejo; Y sobre el arreglamiento del Archivo Secreto del Tribunal".

Además, se veía necesario el nombramiento de un secretario que sirviese en la redacción de los acuerdos, la remisión de oficios y la formación de consultas. Cuando menos, parecía imprescindible el auxilio de un escribiente. Siguiendo con esta serie de obstáculos que volvían intransitable el camino que debía recorrer la Junta para elaborar unas nuevas ordenanzas del Consejo, Ayala señalaba que la Junta tenía noticias de que don Silvestre Collar, secretario del Perú, había formado un plan ordenado para el gobierno de sus oficinas, por lo que poco o nada se podía añadir al respecto. Por su parte, el secretario de Nueva España también había redactado unas normas para el correcto funcionamiento de su departamento.

Ayala terminaba sus apuntes llamando la atención sobre una circunstancia que, a la postre, sería decisiva en la disolución de esta Junta: la extinción de la Junta que se encargaba de redactar el Nuevo Código de Leyes de Indias. 


\section{La extinción de la Junta}

En cumplimiento del último acuerdo adoptado, la Junta encargada de la formación de las nuevas ordenanzas del Consejo de Indias, dirigió una consulta al gobernador del Consejo, con fecha de 13 de mayo de 1802, en la que exponía las dificultades que imposibilitaban la continuación del trabajo que hasta entonces había desarrollado.52

La Junta comenzaba su escrito recordando los motivos que justificaron su constitución y la primera consulta que elevó al gobernador del Consejo, con la respuesta que recibió aprobada por la Junta de Estado, a la que ya hicimos referencia en su momento. A continuación, exponía uno detrás de otro los inconvenientes que hacían inviable el proyecto para cuya realización se había constituido. Así, en primer lugar, reconocían que

"siendo ya Leyes la mayor parte de ellas (de las ordenanzas), y haviendo extinguido
S.M. la otra Junta del nuevo Codigo (...) mira la Junta como moral imposible la orga-
nización de ordenanzas, si estas como expresamente se manda, han de conciliarse con
aquellas, porque no estando formadas, y teniendo por inutiles al intento las de la
actual Recopilacion, derogadas en la mayor parte, será un obstáculo gravísimo para
la Junta caminar bajo un principio incierto...".

Otra circunstancia que disuadía de continuar con el trabajo era los problemas que planteaba la delimitación de competencias entre la antigua Secretaría de Estado y del Despacho de Indias y el Consejo. Sobre este extremo, la Junta ya había solicitado el parecer del gobernador en su primera consulta de 25 de diciembre de 1790 . Por otra parte, se señalaba que en los discursos de apertura de curso, el gobernador describía con precisión las obligaciones de todos los que integraban el tribunal. De esta manera, las dudas que planteaban las antiguas ordenanzas podían ser fácilmente resueltas en la práctica a partir de estos discursos. También el establecimiento de los aranceles que debían percibir las Secretarías del Consejo, la Escribanía de Cámara, los relatores y agentes fiscales y el archivo de Sevilla planteaba numerosos problemas. Esta situación se agravaba en el caso de la contaduría, que de hecho y de derecho, se hallaba cada vez más alejada del control del Consejo. En este sentido, era opinión de la Junta que el título de leyes dirigido a los contadores del Consejo había caducado por las posteriores resoluciones reales. Además, en opinión de la Junta, para la formación de los citados aranceles "es escusado ordenanza, y basta un quaderno

52 AGI, Indiferente General, 885. 
particular". Por consiguiente, la Junta concluía afirmando "la imposibilidad de llenar los deseos del rey hasta tanto que el Nuevo Codigo tenga su perfeccion, y con Leyes ciertas pueda establecerse un Plan que en manera alguna se oponga a ellas". Por todo ello, solicitaba cesar en su cometido, hasta que nuevas circunstancias posibilitaran la realización del trabajo que se le había encomendado. La consulta venía firmada por Jorge Escovedo, Manuel José de Ayala, Miguel Calixto de Acedo y el conde de Torres Muzquiz.

El marqués de Bajamar recibió la consulta junto con los demás papeles, y lo remitió todo al rey mediante consulta de 1 de junio de 1802. En ésta, el gobernador del Consejo, tras exponer al monarca todos los argumentos esgrimidos por la Junta, daba su parecer. En este sentido, el ministro entendía que la formación de unas nuevas ordenanzas no sólo daría lugar a una obra excesivamente voluminosa, sino que además estaría expuesta a continuas variaciones que alterarían lo expuesto en su momento como regla fija. Esta reflexión — precisaba Porlier — se apoyaba en la experiencia acumulada con la formación del Nuevo Código de Leyes de Indias. Así, tras ocho o nueve años de trabajo sólo se había concluido el primer libro. Por todo ello, el dictamen del gobernador del Consejo era favorable a la extinción de la Junta. La resolución del rey, anotada a continuación del extracto de la consulta formulada por el marqués de Bajamar, acogía la petición de la Junta y, tras decretar su cese, ordenaba al Consejo que se encargase del arreglo de los aranceles a los que la Junta había hecho referencia en su consulta de 13 de mayo de 1802. De esta manera, después de mucho trabajo y escaso fruto se extinguió la Junta creada doce años antes para elaborar unas nuevas ordenanzas del Consejo de Indias.

\section{Conclusiones}

El trabajo realizado por la Junta para la elaboración de unas nuevas ordenanzas pudo parecer estéril tanto a los consejeros que integraban aquélla como a sus contemporáneos, pues no contribuyó a mejorar la organización y el funcionamiento del Consejo de Indias. Desde este punto de vista podemos afirmar que el intento frustrado de elaboración de unas nuevas ordenanzas del Consejo, que sustituyeran a las de 1636, no alteró la vida de este tribunal en el tránsito del siglo XVIII al XIX. Sin embargo, transcurridos dos siglos desde que Carlos IV decidiera decretar su cese, los materia- 
les reunidos por esta Junta adquieren un notable valor para los estudiosos del Supremo Tribunal de Indias en las postrimerías del Antiguo Régimen.

En efecto, además de permitir en buena medida calibrar la vigencia de muchas de las disposiciones que se recogían en la Recopilación de 1680, todavía en vigor en este tiempo, las afirmaciones contenidas en las propuestas que los miembros de la Junta realizaron en las distintas sesiones, y el análisis de los problemas con los que tuvieron que enfrentarse, iluminan la realidad de una institución que parece renacer en la segunda mitad del siglo XVIII. ${ }^{53}$ A través del estudio de los trabajos realizados por la Junta se percibe la realidad de una institución que mantiene una vitalidad y una pujanza poco compatibles con la visión que algunos autores han querido transmitir de la historia del Consejo de Indias en el siglo XVIII. ${ }^{54}$ Así, por ejemplo, los problemas de delimitación de competencias con la Secretaría de Estado y del Despacho de Indias ponen en entredicho la aplicación en toda su extensión de los decretos de 20 de enero y 11 de septiembre de 1717, que, como señalamos en su momento, arrebataron al Consejo un gran número de atribuciones en beneficio de la Secretaría del Despacho de Indias.

Por otra parte, la consulta que la Junta realizó el 25 de diciembre de 1790 arroja algunas luces sobre la creciente importancia de la contaduría general de Indias en el siglo XVIII y su progresiva separación institucional del Consejo. El acceso de la contaduría a la vía reservada suponía, de hecho, la sustracción al conocimiento del Consejo de muchos de los asuntos que ésta tramitaba y una pérdida evidente de la influencia que tradicionalmente el Consejo había ejercido sobre la misma.

Por todo lo anterior, el estudio de los trabajos de la Junta encargada de elaborar unas nuevas ordenanzas del Consejo de Indias supone un paso más en el conocimiento de esta importante institución en el siglo XVIII.

53 En este sentido se pronuncia Burkholder, Mark A.: "The Council of the Indies in the Late Eighteenth Century: a new perspective", Hispanic American Historical Review, vol. 56, n. ' 3, Durham, August 1976, págs. 404-423.

54 Véase en este sentido la citada y, por otra parte valiosa, obra de Bernard: Le Secrétariat... 